\section{ADOPTING SHARED RESPONSIBILITY IN ACCIDENT PREVENTION AT A MINE IN ZIMBABWE THROUGH DEVELOPMENT AND ADOPTION OF SHE PACTS}

Blessing Garamumhango*. Mimosa Mining Company, Zvishavane, Zimbabwe

\subsection{6/oemed-2018-ICOHabstracts.708}

Introduction The management of occupational safety and health requires a shared approach among team members to be effective. After experiencing a number of accidents, the safety, health and environment (SHE) cluster came up with an initiative of developing SHE pacts within teams at the mine. These pacts were binding and were based upon a shared vision and values for the team and were supported by a set of critical behaviours to address identified focal risks faced by the team. Methods An external facilitator who is a specialist in behavioural based safety approaches was engaged to roll-out the program over a period of three months. The facilitator played a background role in the process letting the team members come up with their top five risks and the set of behaviours needed to address the risks and the values needed to sustain those behaviours overtime and the overall vision for the team. The SHE pact was signed off by all for commitment and accountability. The document was framed and put on the noticeboards of the team's work area with a photograph of all the team members and their signatures.

Result Acceptability of the SHE pact by the teams was high. The end points for usage within teams was defined by the number of stop and fixes carried out, the number of SHE related observations/inspections carried out by team members, commendations/rewards for SHE observations, near miss reporting statistics and supervisor inspections. There was a notable increase of these leading indicators after the adoption of the SHE pacts.

Discussion Behaviour based safety interventions are important to address the soft issues in SHE management. The focus on leading indicators is important in cultivating a culture of prevention within the workplace.

\section{REFERENCE}

Available on request

\section{HEALTH EVALUATION FOR OCCUPATIONAL HIGH- ALTITUDE EXPOSURE: RESULTS FROM A CHILEAN COPPER MINE DURING 2016}

\section{1,2Méndez José. 'Codelco Chile, División Andina, Los Andes, Chile; ${ }^{2}$ Society of Occupational Medicine of Chile, Santiago, Chile}

\subsection{6/oemed-2018-ICOHabstracts.709}

Introduction Since 2013 in Chile a specific occupational evaluation, determined by Ministry of Health, is required to work in high altitude (defined as 3000 to 5500 metres above sea level). The aim of this study was to describe the results of health evaluation for high-altitude work in a Chilean copper mine during year 2016.

Methods Health evaluations performed during 2016 in Andina Division of Codelco, the Chilean Public Mining Company, were analysed. All medical contraindications for high- altitude work were checked and classified into categories. Time to recover medical aptitude for work was calculated.
Results From 1542 workers exposed to high altitude work, 1483 underwent medical evaluation according to Chilean regulation during 2016. This evaluation included: medical history, modified Lake-Louise questionnaire, EKG, chest X-rays and blood tests (haemoglobin, plasmatic creatinine, lipid panel and glucose level). 29 workers (1.96\% of all evaluated) had a permanent contraindication for working at high altitude: 15 of them due to cardiologic conditions (ischaemic heart disease mainly); 6 of them due to unstable diabetes mellitus; 3 of them had respiratory diseases (COPD) and the other 5 had other specific conditions (chronic liver disease, stroke with motor impairment, refractory epilepsy, severe psychiatric disorder and polycithemia vera). These workers were relocated in middle or low-altitude positions. 167 workers $(11.26 \%$ of all evaluated) had a temporary contraindication for high-altitude work. The average duration of the working restriction was 11 days until the condition was treated. 143 (86\%) were cardiovascular and metabolic conditions: high blood pressure, hyperglycemia, severe obesity and dyslipidemia. 13 workers $(0.88 \%)$ had high levels of haemoglobin and underwent specific additional exams to find secondary causes. Only 2 of them were diagnosed as Occupational Polycythemia, which is one of the three high-altitude related occupational diseases recognised by Chilean law.

Discussion High-altitude Occupational Polycythemia prevalence was $0.1 \%$ in our Company, which is lower than other series. This might be explained because of the type of work-shifts that allow workers to sleep everyday under 1000 metres above sea level. Cardiovascular and metabolic conditions were the most frequent causes of contraindication to work, which is explained by the high prevalence of chronic diseases and cardiovascular risk factors in Chilean population.

\section{RESPIRATORY IMPAIRMENT AND PERSONAL RESPIRABLE DUST EXPOSURE LEVELS AMONG MINERS IN A GOLD MINE-TANZANIA}

Matilda Rusibamayila*, Simon Mamuya. Muhimbili University of Health and Allied Sciences, Dar-es-Salaam, Tanzania

\subsection{6/oemed-2018-ICOHabstracts.710}

Introduction Mining is one of the most hazardous sectors to work in because it is a sector that predisposes workers to various hazards including dust. Exposure to dust in the mines is inevitable because the whole process of extracting gold has to involve rock breaking. This dust can penetrate up to the alveoli of the pulmonary system and cause respiratory impairment.

Methods Cross-sectional study design was used employing use of questionnaires for data collection on respiratory symptoms. Lung functions were measured using spirometry. Personal respirable dust exposure was collected from similar exposure groups using air sampling pumps. A simple random sampling technique was used to select participants. 112 workers were included in the study. Data analysis was done using SPSS computer software version 16.0.

Results The overall Geometric Mean of respirable dust was $0.26 \mathrm{mg} / \mathrm{m}^{3} \quad(\mathrm{GSD}=0.32)$ over a mean sampling time of 8 hours (with a range between 7-11 hours). The GM for underground and open pit were $0.41 \mathrm{mg} / \mathrm{m}^{3} \quad(\mathrm{GSD}=0.28)$ and $0.17 \mathrm{mg} / \mathrm{m}^{3} \quad(\mathrm{GSD}=0.23)$ respectively. For underground, the 
GM was highest among bogger operators $0.53 \mathrm{mg} / \mathrm{m}^{3}$ $(G S D=0.27)$ and the least among truck operators 0.29 $(G S D=0.37)$. While for open pit, the highest GM was found among quality controllers $0.39 \mathrm{mg} / \mathrm{m}^{3} \quad(\mathrm{GSD}=0.18)$ and the least among in truck operators $0.13 \mathrm{mg} / \mathrm{m}^{3}(\mathrm{GSD}=0.15)$. Respiratory symptoms were phlegm (49.1\%), Breathlessness (42.9\%), cough (37.5\%), wheezing (18.8\%) and chest tightness $(10.7 \%)$. Prevalence of airflow obstruction (FEV1/FVC $<0.75$ ) was $7.7 \%$ among non smoking miners.

Discussion Despite the fact that levels of respirable dust exposure were below recommended occupational exposure limits, prevalence of respiratory symptoms was still high among gold miners. There is a need to conduct further studies on quarts.

\section{EFFECTIVENESS OF PARTICIPATORY ERGONOMIC INTERVENTIONS AND A MUSCULOSKELETAL DISORDER PREVENTION PROGRAM ON THE REDUCTION OF MUSCULOSKELETAL RISK-FACTORS IN CORE-SHACK OPERATIONS}

\author{
${ }^{1,2} \mathrm{~K}$ Whelan, ${ }^{1,2} \mathrm{~T}$ Eger. 'Laurentian University, Sudbury, Canada; ${ }^{2}$ Centre for Research in \\ Occupational Safety and Health, Sudbury, Canada

\subsection{6/oemed-2018-ICOHabstracts.711}

Introduction Workplace musculoskeletal disorders (WMSDs) give rise to approximately $44 \%$ of compensation claims each year within the Canadian mining sector. Despite the immensity of reported WMSDs little research has been conducted within said population. The purpose of this study is to examine the effectiveness of physical ergonomic interventions and a participatory MSD prevention program on the reduction of MSD risk-factors within core-shack operators. Anecdotal evidence suggests that the awkward postures, excessive force requirements, and repetitive material handling found within coreshack operations may be placing workers at a greater risk for MSD development; however, no previous research has been conducted.

Methods Amalgamation of observational based MSD screening tools and direct joint-angle measurements via a mobile movement analysis and motion capture system (NOTCH) will be used. Siemens Classic Jack human modelling software will be utilised to provide ergonomic assessments within a simulated environment. Resultant data will be used to develop targeted physical ergonomic interventions to mitigate MSD risk-factors within at-risk tasks. The Occupational Health and Safety Council of Ontario (OHSCO) MSD Prevention Toolbox 3C and New South Wales Mine Safety and Advisory Committee MSD Prevention Guide will be used as a reference for the development of a participatory MSD Prevention Program.

Result It is anticipated that the implementation of targeted workplace ergonomic interventions in conjunction with a participatory MSD prevention program will provide a comprehensive approach to MSD risk factor identification and prevention strategies. Moreover, it is expected that the intervention components will increase communication and decision latitude within core-shack operations.

Discussion The prevalence of musculoskeletal injuries with the Canadian mining industry is of particular concern. The dissemination of this study will be shared with participating mines so improvements can be made to aide in worker health and safety and prevention of musculoskeletal injuries.
40

PROMOTING HEALTHY LIFESTYLES IN AN OPEN PIT COAL MINE

H Piedrahita. Carbones del Cerrejón, Limited - Colombia

\subsection{6/oemed-2018-ICOHabstracts.712}

Introduction Open pit coal mines face different occupational risks, however little attention has been placed on the importance of promoting in the labour and social sphere of workers healthy lifestyles. In an open coal mine in Colombia and with the goal to prevent general and occupational diseases and overall to improve quality of life, was developed a participatory and integrated program focused in promoting healthy lifestyles.

Methods A company team spent nearly six months in the first half of 2013 in developing the program. The team comprised members of the Occupational Health Committee, leaders from the trade union and representatives from various operational and administrative areas. The final outcome of this preparatory work was the model guiding this program, which has three main central and transverse pillars: physical activity, healthy nutrition, and related education. Physical activity is the model's most important bulwark.

Result The program was finally implemented in 2015 in all the settlements of region where the workers reside reaching an adherent level of 1818 people, demonstrating its widespread acceptance amongst employees and their families. In 2017 there are more than 3000 participants and at the end of 2016, despite the short period since implementation, overweight and obesity levels had fallen by $3.75 \%$ and triglyceride levels had dropped by $6.9 \%$ (cholesterol was unchanged). Program adherence has remained steady at $70 \%$ since the start of the pilot test as well as throughout the year and a half of the program itself.

Discussion Considering that other similar initiatives reach maximums of $45 \%-50 \%$, this program's adherence is quite successful. Throughout 2015 and 2016, there were more than 100,200 hours of activities with 91710 participant attendances. The program has strengthened ties amongst the participants and communities involved, which has been reflected in interactions on social networks showing various activities held at different locations.

\section{HEALTH AND SAFETY TRAINING ON LEAD EXPOSURE FOR ARTISANAL AND SMALL-SCALE GOLD MINERS IN ZAMFARA STATE, NIGERIA}

${ }^{1}$ Kadiri Shamusideen*, ${ }^{2}$ Sels Dakwak. 'Principal Consultant, Zub Chord Technical Ventures, Lagos Nigeria; ${ }^{2}$ Deputy Director, Industrial Training Fund, Jos Nigeria

\subsection{6/oemed-2018-ICOHabstracts.713}

Introduction Artisanal and small-scale gold mining (ASGM) has long been practiced in Nigeria. Mining often involves both occupational and community health and safety hazards that not only affect miners, but also their families and communities. In Zamfara, Nigeria where the gold bearing deposits contain unusually problematic concentrations of lead these are overwhelmed by the enormous effects of lead poisoning. In 2010, unregulated small-scale miners in Zamfara state, gave rise to an epidemic of childhood lead poisoning, with at least four hundred children under the age of five dying within a six-month period (a number that rose to over 700 by 2013). It was found out that a lack of training in Health and safety and support to the ASGM sector, and the need for the miners 